\title{
In vivo insulin resistance in individual peripheral tissues of the high fat fed rat: assessment by euglycaemic clamp plus deoxyglucose administration
}

\author{
E.W. Kraegen, D. E. James, L. H. Storlien, K. M. Burleigh and D.J.Chisholm \\ Garvan Institute of Medical Research, St Vincent's Hospital, Sydney, Australia
}

\begin{abstract}
Summary. We have examined peripheral insulin action in conscious rats chronically fed high fat $(60 \%$ calories as fat) or high carbohydrate (lab chow) diets using the euglycaemic clamp plus $3 \mathrm{H}$-2-deoxyglucose technique. A response parameter of individual tissue glucose metabolic rate (the glucose metabolic index, based on tissue deoxyglucose phosphorylation) was used to assess diet effects in eight skeletal muscle types, heart, lung and white and brown adipose tissue. Comparing high fat with high carbohydrate fed rats, basal glucose metabolism was only mildly reduced in skeletal muscle (only diaphragm was significant, $p<0.05$ ), but was more substantially reduced in other tissues (e.g. white adipose tissue $61 \%$ and heart $33 \%$ ). No evidence of basal hyperinsulinaemia was found. In contrast, widespread insulin resistance was found during the hyperinsulinaemic clamp $(150 \mathrm{mU} / \mathrm{l})$ in high fat fed animals; mean whole body net glucose utilization was $34 \%$ lower $(p<0.01)$, and the glucose metabolic index was
\end{abstract}

lower in skeletal muscle (14 to $56 \%, p<0.05$ in 6 out of 8 muscles), white adipose $(27 \%, p<0.05)$ and brown adipose tissue $(76 \%, p<0.01)$. The glucose metabolic index was also lower at maximal insulin levels in muscle and fat, suggesting the major effect of a high fat diet was a loss of insulin responsiveness. White adipose tissue differed from muscle in that incremental responses (maximal insulin minus basal) were not reduced by high fat feeding. The heart showed an effect opposite to other tissues, with an increase in insulin-stimulated glucose metabolism in high fat versus chow fed rats. We conclude that high fat feeding, without a major increase in body weight or basal hyperinsulinaemia, causes widespread but varying degrees of in vivo insulin resistance in peripheral tissues, with major effects in principally oxidative skeletal muscle.

Key words: Diet, insulin action, muscle, glucose metabolism.
Previous studies in man have suggested that a diet high in fat content leads to reduced glucose tolerance [1,2]. Glucose intolerance can also be induced by short-term feeding of a high fat diet to the laboratory rat [3-5], and further in vitro studies [6-9] would suggest that the glucose intolerance is mediated, at least in part, by resistance to insulin action in peripheral tissues. However, neither the tissue specificity of insulin resistance nor the magnitude of impairment at the whole body level have been identified. In view of the high average fat component of around $40 \%$ in the Western diet and a possible link between diet-induced and other forms of insulin resistance, we considered it important to identify which tissues are most affected by a high fat diet.

There are reports of reduced basal and/or insulinstimulated glucose uptake in isolated adipocytes [7, 10-12]. However, adipose tissue contributes little to overall glucose disposal [13,14]. Other in vitro studies have demonstrated impaired basal and/or insulin-stimulated glucose uptake in diaphragm [7], soleus muscle
[8] and heart [9]. It is therefore to be expected that the muscle mass, a major determinant of whole body glucose disposal $[15,16]$, will show some in vivo insulin resistance following high fat feeding. However, the tissue specificity and biochemical mechanisms involved have not been elucidated. In fact, there has been no direct demonstration of in vivo insulin resistance in muscles of high fat fed animals. In the only in vivo study of which we are aware [7], it was not possible to demonstrate reduced incorporation of $14 \mathrm{C}$-glucose into diaphragm glycogen in the high fat group. Furthermore, in view of the heterogeneity of insulin sensitivity among individual muscles [16], it is clearly desirable to examine a number of different muscles in order to properly characterise the diet effect.

We have previously adapted the euglycaemic clamp technique for use in the laboratory rat [17]. More recently we have extended the technique by administration of labelled 2-deoxyglucose to study in vivo insulin action simultaneously at the whole body level and within indi- 
Table 1. Composition of diets

\begin{tabular}{llllll}
\hline & \multicolumn{2}{l}{$\begin{array}{l}\text { Laboratory } \\
\text { chow }\end{array}$} & & \multicolumn{3}{c}{ High fat diet } \\
\cline { 2 - 3 } \cline { 5 - 6 } & $\%$ Weight & $\%$ kcal & & \% Weight & $\%$ kcal \\
\hline Protein & 22 & 23 & 26 & 20 \\
Carbohydrate & 62 & 65 & 26 & 20 \\
Fat & 5.5 & 12 & 35 & 60 \\
Non-caloric & 10.5 & - & 13 & - \\
$\quad$ component & & & & \\
\hline
\end{tabular}

Rats were maintained on diets shown for 21-23 days prior to acute study. Average daily intakes were $75 \pm 2$ and $93 \pm 1 \mathrm{kcal}$ for laboratory chow and high fat diets respectively

vidual tissues of the conscious unrestrained rat [14]. The present studies were performed to examine the effects of high fat feeding on basal and insulin-stimulated glucose utilization in a number of different peripheral tissues in vivo.

\section{Materials and methods}

\section{Experimental animals and diets}

Male Wistar rats bred and raised in our own colony, with free access to a standard laboratory chow (Bavestock Feeds, Melbourne, Australia) and water, subject to controlled lighting (lights on from 06.00 to $18.00 \mathrm{~h})$ and temperature $\left(22 \pm 1{ }^{\circ} \mathrm{C}\right)$, were used for study. Twenty-one to 23 days prior to acute study, a randomly selected group was transferred to a specially prepared high fat diet. Details of the high fat and the chow diet are shown in Table 1. All animals were between 90 and 120 days old at the time of acute study. Seven additional rats from each diet group were randomly chosen to examine the effects of diet on tissue weights.

\section{Euglycaemic clamp studies}

All rats for metabolic study were anaesthetised intraperitoneally with pentobarbitone $(20 \mathrm{mg} / \mathrm{kg})$ and intramuscularly with ketamine hydrochloride $(25 \mathrm{mg} / \mathrm{kg})$ and fitted with two chronic intravenous cannulae as previously described $[14,17]$. Studies were conducted $48 \mathrm{~h}$ after surgery in unrestrained conscious rats. Rats were deprived of food for $5 \mathrm{~h}$ prior to commencement of acute study at approximately 10.00 hours.

Euglycaemic hyperinsulinaemic clamps were performed as described previously [14]. Briefly, continuous infusions of either 4.1 or $33 \mathrm{mU} \cdot \mathrm{kg}^{-1} \cdot \mathrm{min}^{-1}$ neutral porcine insulin (Actrapid, Novo Industrie, Bagsvaerd, Denmark) were infused for $2 \mathrm{~h}$; these rates produce insulin levels in the upper physiological range and a maximal response respectively [14]. The arterial (carotid) blood glucose concentration was clamped at the basal fasting level using a variable rate $30 \%$ glucose infusion delivered via the jugular cannula. The glucose infusion rate during the second hour of the clamp $\left(\mathrm{GIR}_{60-120}\right)$ was taken as the response parameter of the potency of whole body insulin action. Blood samples $(0.4 \mathrm{ml})$ were obtained for insulin determination in all clamp studies at 0,60 and $120 \mathrm{~min}$. Red blood cells were resuspended and returned to the rat after the 0 and $60 \mathrm{~min}$ samples.

\section{In vivo insulin action in individual tissues}

Insulin action within individual tissues in vivo was studied using the nonmetabolisable glucose analog 2,6-(3H)-2-deoxyglucose (3H-2DG) as described previously [14]. 3H-2DG was administered as an $80 \mu \mathrm{Ci}$ iv bolus at $75 \mathrm{~min}$ after the commencement of the glucose clamp. The $3 \mathrm{H}-2 \mathrm{DG}$ bolus was also administered without insulin infusion to
5 rats from each of the high fat and chow fed groups in order to study basal glucose metabolic rate. Blood samples for determination of blood and plasma glucose concentrations and plasma $3 \mathrm{H}-2 \mathrm{DG}$ concentrations were obtained at 2, 5, 10,15, 20,30 and $45 \mathrm{~min}$ after bolus $3 \mathrm{H}-2 \mathrm{DG}$ administration.

At the completion of the clamp rats were intravenously anaesthetised (pentobarbitone, $60 \mathrm{mg} / \mathrm{kg}$ ) and the following skeletal muscles were rapidly removed and frozen in liquid nitrogen for subsequent analysis: soleus (containing mainly slow-twitch oxidative fibres), superficial or white parts of the gastrocnemius and quadriceps (containing mainly fast-twitch glycolytic fibres), deep red portions of the gastrocnemius and quadriceps (containing mainly fast-twitch oxidativeglycolytic and slow-twitch oxidative fibres) and extensor digitorum longus (EDL) and plantaris (both containing a mixture of fast-twitch oxidative-glycolytic and glycolytic fibres) and diaphragm (containing a mixture of all three muscle fibres) [19].

In addition, the following organs or tissue samples were rapidly removed and frozen: lung, heart, white (epididymal fat pads) and brown (interscapular) adipose tissue.

An estimate of tissue glucose metabolic rate (the glucose metabolic index, $\operatorname{Rg}^{\prime}$ ) was calculated using the following expression [17]:

$\mathrm{Rg}^{\prime}=\frac{\mathrm{Cp} \cdot \mathrm{Cm}^{*}(45)}{\int_{0}^{45} \mathrm{Cp} *(\mathrm{t}) \mathrm{dt}}$

where $\mathrm{Cp}$ is the plasma glucose level during the euglycaemic clamp; $\mathrm{Cm}^{*}[45]$ is the tissue accumulation per unit wet tissue mass of $3 \mathrm{H}$ 2-deoxyglucose-6-phosphate at $45 \mathrm{~min}$ after tracer administration;

45

$\int_{0}^{45} \mathrm{Cp}^{*}(\mathrm{t}) \mathrm{dt}$ is the area under the plasma $3 \mathrm{H}-2 \mathrm{DG}$ curve over the 45-min period following tracer administration;

$\mathrm{t}=0$ when the tracer bolus is administered.

A detailed description of the methodology and the assumptions involved in calculating $\mathrm{Rg}^{\prime}$ in individual tissues has been reported elsewhere [14]. Additional recent evidence suggests that $\mathrm{Rg}^{\prime}$ is close to true glucose metabolic rate in muscle [18].

\section{Analytical methods}

Plasma samples for determination of $3 \mathrm{H}-2 \mathrm{DG}$ concentration were deproteinised immediately in $5.5 \% \mathrm{ZnSO} 4$ and saturated $\mathrm{Ba}(\mathrm{OH}) 2$. An aliquot of the supernatant was added to scintillant for counting in a liquid scintillation spectrometer. Blood and plasma glucose concentrations were measured using a glucose analyser (Model 23AM Yellow Springs Instruments, Yellow Springs, OH, USA). Plasma samples for insulin determination were stored at $-20^{\circ} \mathrm{C}$ until analysed by a double antibody radioimmunoassay as described previously [17]. All counting of radioactivity was performed in a liquid scintillation spectrometer (Beckman Instruments, Irvine, CA, USA) using a quench corrected (external standard) counting program. Radioactivity in aqueous samples was counted in Picofluor scintillant (Packard Instruments, Sydney, Australia).

\section{Statistical analysis}

Statistical analysis was performed using an unpaired one-tailed Student's t-test. Group means are shown with SEM unless otherwise stated.

\section{Results}

\section{Effects of diet on body parameters and basal glucose and insulin levels}

Table 2 shows body weight, tissue weights and basal glucose and insulin levels in the two diet groups. Over the period on diet, body weight increased marginally 
Table 2. The effect of diet on body weight, tissue weights and glucose and insulin levels

\begin{tabular}{|c|c|c|}
\hline & Chow fed & High fat fed \\
\hline \multicolumn{3}{|l|}{ Body weight (g) } \\
\hline Initial & \pm 10 & 307 \\
\hline Final & \pm 12 & 405 \\
\hline \multicolumn{3}{|l|}{ Tissue wet weights (g) } \\
\hline Epididymal fat & $4.6 \pm 0.6$ & $6.8 \pm 0.6^{\mathrm{a}}$ \\
\hline Interscapular brown fat & $0.25 \pm 0.02$ & $0.40 \pm 0.07^{\circ}$ \\
\hline Soleus & $0.19 \pm 0.01$ & $0.17 \pm 0.01$ \\
\hline $\begin{array}{l}\text { Extensob digitorum } \\
\text { longus (EDL) }\end{array}$ & $0.17 \pm 0.01$ & $0.18 \pm 0.01$ \\
\hline $\begin{array}{l}\text { Basal blood glucose } \\
(\mathrm{mmol} / \mathrm{l})\end{array}$ & $4.4 \pm 0.1$ & $4.6 \pm 0.1$ \\
\hline $\begin{array}{l}\text { Basal plasma insulin } \\
(\mathrm{mU} / 1)\end{array}$ & $36 \pm 4$ & \pm 3 \\
\hline
\end{tabular}

All parameters with the exception of initial body weight are at the time of acute study following diet pretreatment. Means $\pm S E$ are shown. Group sizes are 7 to 12 animals.

${ }^{a} p<0.05,{ }^{b} p<0.01$ compared with chow fed rats

Table 3. The euglycaemic clamp in chow (high carbohydrate) and high fat fed rats

\begin{tabular}{|c|c|c|c|c|}
\hline & \multicolumn{2}{|c|}{$\begin{array}{l}\text { Midrange insulin } \\
\left(4.1 \mathrm{mU} \cdot \mathrm{kg}^{-1} \cdot \mathrm{min}^{-1}\right)\end{array}$} & \multicolumn{2}{|c|}{$\begin{array}{l}\text { Maximal insulin } \\
\left(33 \mathrm{mU} \cdot \mathrm{kg}^{-1} \cdot \mathrm{min}^{-1}\right)\end{array}$} \\
\hline & $\begin{array}{l}\text { Chow } \\
\text { fed } \\
(n=7)\end{array}$ & $\begin{array}{l}\text { High fat } \\
\text { fed } \\
(n=6)\end{array}$ & $\begin{array}{l}\text { Chow } \\
\text { fed } \\
(n=10)\end{array}$ & $\begin{array}{l}\text { High fat } \\
\text { fed } \\
(n=5)\end{array}$ \\
\hline \multicolumn{5}{|c|}{ Blood glucose $(\mathrm{mmol} / \mathrm{l})$} \\
\hline Basal & $4.2 \pm 0.1$ & $4.6 \pm 0.1$ & $4.4 \pm 0.1$ & $4.5 \pm 0.1$ \\
\hline $\operatorname{Mean}_{60-120}$ & $4.3 \pm 0.1$ & $4.7 \pm 0.1$ & $4.4 \pm 0.1$ & $4.6 \pm 0.1$ \\
\hline $\begin{array}{l}\text { Coefficient of } \\
\text { variation } \\
(\%)_{60-120}\end{array}$ & $5.7 \pm 0.8$ & $6.5 \pm 0.9$ & $7.3 \pm 0.8$ & $6.5 \pm 0.6$ \\
\hline \multicolumn{5}{|c|}{ Plasma insulin $(\mathrm{mU} / 1)$} \\
\hline $\operatorname{Mean}_{60-120}$ & $127 \pm 7$ & $146 \pm 9$ & $2190 \pm 110$ & $1940 \pm 200$ \\
\hline \multicolumn{5}{|c|}{ Glucose infusion rate } \\
\hline $\begin{array}{l}\mathrm{GIR}_{60-120} \\
\left(\mathrm{mg} \cdot \mathrm{kg}^{-1} \cdot \min \right.\end{array}$ & $16.6 \pm 0.8$ & $10.9 \pm 0.8^{b}$ & $27.6 \pm 0.9$ & $24.3 \pm 1.2^{\mathrm{a}}$ \\
\hline
\end{tabular}

${ }^{\mathrm{a}} p<0.05,{ }^{\mathrm{b}} p<0.01$ compared with chow fed group

but not significantly more in the high fat fed group. Analysis of final individual tissue weights in fat versus chow fed rats revealed significantly higher epididymal and interscapular fat weights (50 and 60\% higher respectively), but no significant difference in soleus and EDL muscle weights. There were no significant differences between either basal blood glucose or between basal insulin levels in the two diet groups.

\section{Euglycaemic clamp: whole body responses}

Table 3 shows data relevant to, and obtained in, euglycaemic clamps performed in high fat and chow fed rats during either 4.1 (mid) or $33(\max ) \mathrm{mU} \cdot \mathrm{kg}^{-1} \cdot \mathrm{min}^{-1}$ insulin infusions. Blood glucose levels during the final

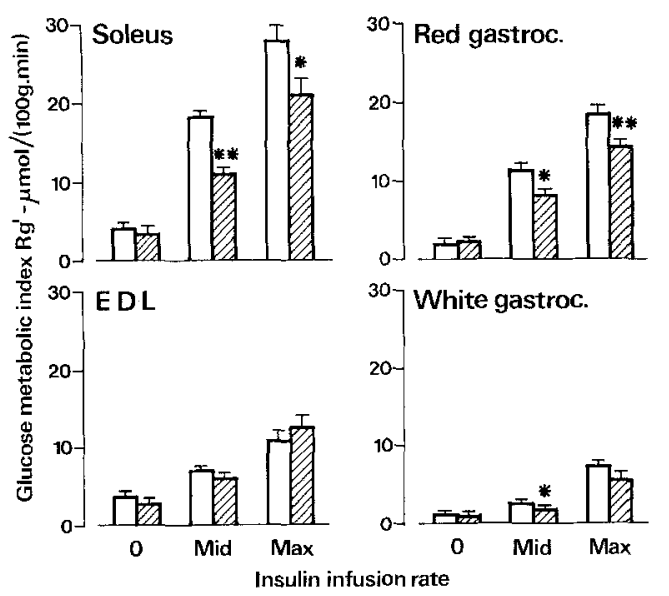

Fig. 1. Effects of diet pretreatment on glucose metabolic index in hindlimb skeletal muscles during basal and hyperinsulinaemic euglycaemic states in conscious rats. Insulin infusion rates are: mid, $4.1 \mathrm{mU}$. $\mathrm{kg}^{-1} \cdot \min ^{-1} ; \max , 33 \mathrm{mU} \cdot \mathrm{kg}^{-1} \cdot \mathrm{min}^{-1}$. Open histograms are chow (high carbohydrate) fed rats, shaded histograms are high fat fed rats. Gastroc., gastrocnemius: EDL, extensor digitorum longus. Means \pm SE shown ${ }^{*} p<0.05,{ }^{* *} p<0.01$ compared to chow fed animals

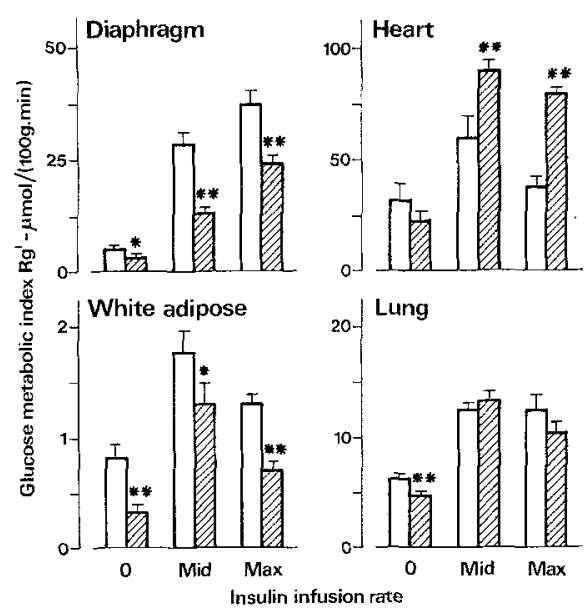

Fig.2. As for Figure 1 but showing responses in diaphragm, heart, lung and white adipose tissue (epididymal fat pad). Note that the vertical scales for $\mathrm{Rg}^{\prime}$ differ from Figure $1 .{ }^{*} p<0.05,{ }^{* *} p<0.01 \mathrm{com}-$ pared to chow fed animals

hour of all clamps were close to the respective basal levels in all studies. There was evidence of diminished whole body response to both levels of insulin elevation in the high fat group. Despite marginally higher insulin levels produced by the midrange insulin infusion rate, the mean glucose infusion rate (GIR) required to maintain euglycaemia was reduced by $34 \%$ compared with chow fed rats. The fact that a reduction in whole body glucose disposal $(\mathrm{Rd})$ contributed to the reduced GIR was supported by the higher mean value found for the term $\int_{0}^{45} C p^{*}(t) d t$ (see Eq. 1) in the high fat versus chow group $(18.9 \pm 0.7$ versus $14.2 \pm 0.4 \mathrm{dpm}$ $\mathrm{ml}^{-1} \mathrm{~min}^{-1} \times 10^{-6}$, corrected for dose of $10^{8} \mathrm{dpm}, p<$ $0.025)$. There was also a significant reduction in GIR 
Table 4. Glucose metabolic index in additional tissues

\begin{tabular}{llc}
\hline Tissue & \multicolumn{2}{l}{$\begin{array}{l}\text { Insulin infusion rate } \\
\mathrm{mU} \cdot \mathrm{kg}^{-1} \cdot \mathrm{min}^{-1}\end{array}$} \\
\cline { 2 - 3 } & 0 & \multicolumn{1}{c}{4.1} \\
\hline & \multicolumn{2}{l}{$\begin{array}{l}\text { Glucose metabolic index } \mathrm{Rg}^{\prime} \\
\left(\mu \mathrm{mol} \cdot 100 \mathrm{~g}^{-1} \cdot \mathrm{min}^{-1}\right)\end{array}$} \\
\hline Plantaris & $\mathrm{C} 1.8 \pm 0.2$ & $7.7 \pm 0.7$ \\
Red quadriceps & F $2.0 \pm 0.3$ & $3.4 \pm 0.2^{\mathrm{b}}$ \\
White quadriceps & $\mathrm{C} 2.2 \pm 0.6$ & $14.8 \pm 1.7$ \\
& $\mathrm{~F} 2.6 \pm 0.6$ & $8.5 \pm 1.7^{\mathrm{a}}$ \\
Brown adipose tissue & $\mathrm{C} 1.1 \pm 0.4$ & $4.5 \pm 0.4$ \\
(interscapular) & F $1.0 \pm 0.2$ & $3.5 \pm 0.5$ \\
\hline
\end{tabular}

Effects of diet pretreatment on glucose metabolic index in tissues shown during basal and midrange hyperinsulinaemic euglycaemic states in conscious rats. $\mathrm{C}$ : chow fed, $\mathrm{F}$ : high fat fed animals. Means $\pm \mathrm{SE}$ shown. ${ }^{\mathrm{a}} p<0.05,{ }^{b} p<0.01$ compared with corresponding value in chow fed rats

$(12 \%, p<0.05)$ at a maximally effective insulin elevation in the high fat group.

\section{Individual tissue responses}

Glucose metabolism in individual peripheral tissues was assessed following the bolus of $3 \mathrm{H}-2 \mathrm{DG}$ and subsequent tissue analysis of phosphorylated 3H-2DG. The bolus was administered to the clamped rats detailed in Table 3 , and to additional rats in the basal state from each diet group. Our response parameter indicating glucose metabolic rate, the metabolic index $\mathrm{Rg}^{\prime}$, is calculated from Eq. 1. Rg' for the skeletal muscles soleus, extensor digitorum longus (EDL) and red and white gastrocnemius are displayed in Figure 1 . Figure 2 shows $\mathrm{Rg}^{\prime}$ in diaphragm, heart, lung and white adipose tissue (WAT). In order to provide further evidence for variations in response in different muscle types, several additional muscles were taken in the basal and midrange studies. These are shown in Table 4, together with responses in brown adipose tissue (BAT).

High fat feeding had only a minimal influence on basal glucose uptake in skeletal muscle. Of the eight muscle tissues studied, only diaphragm showed a significant $(p<0.05)$ suppression in basal glucose metabolic rate with high fat feeding (Figs. 1 and 2, Table 4).

During the midrange euglycaemic clamp $\mathrm{Rg}^{\prime}$ increased significantly in all muscles in both groups, the largest increases (3- to 4-fold) occurring in the primarily oxidative muscles: diaphragm, soleus, red gastrocnemius and red quadriceps (Figs. 1 and 2, Table 4). Smaller increases were observed in EDL, white gastrocnemius, plantaris and white quadriceps. A lower $\mathrm{Rg}^{\prime}$ was observed in all muscle groups in the high fat compared to chow fed group, the difference varying from $14 \%$ in
EDL to $56 \%$ in diaphragm. The lower $\mathrm{Rg}^{\prime}$ was statistically significant in six of eight muscle tissues studied. Similarly incremental responses $\left(\mathrm{Rg}^{\prime}\right.$ at midrange insulin minus basal) were reduced in all oxidative muscles. The fractional insulin response in $\mathrm{Rg}^{\prime}$ (insulin-stimulated increase as a multiple of basal) with high fat feeding was less than or equal to that observed in chow fed animals in all muscle groups.

To confirm whether high fat feeding specifically reduced maximal insulin responsiveness in vivo, tissue studies were also performed during the maximal insulin euglycaemic clamp. A significantly reduced $\mathrm{Rg}^{\prime}$ response was found in soleus, red gastrocnemius and diaphragm of high fat fed rats. No significant differences were found in muscles containing a high percentage of glycolytic fibres, namely EDL and white gastrocnemius.

There was considerable variation in basal $\mathrm{Rg}^{\prime}$ among individual tissues in the chow fed group. $\mathrm{Rg}^{\prime}$ in heart was higher, lung and BAT similar, and WAT considerably lower than that observed in skeletal muscle (Fig.2, Table 4). All these tissues exhibited a significantly augmented $\operatorname{Rg}^{\prime}$ during the midrange hyperinsulinaemic euglycaemic clamp. The increase in the chow fed group, as a percentage of basal, in heart, lung and white adipose tissue (each approximately 2-fold) was considerably less than that observed in most of the skeletal muscles. In contrast, BAT (Table 4) was extremely sensitive to insulin elevation, with $\mathrm{Rg}^{\prime}$ increasing more than 10-fold over basal and reaching a value similar to that observed in heart.

The diet effect on $\mathrm{Rg}^{\prime}$ differed among tissues. Heart, lung, WAT and BAT each also differed from the general pattern observed in skeletal muscle. Basal $\mathrm{Rg}^{\prime}$ was reduced by high fat feeding in all these tissues, although this reduction was not quite significant in heart $(p=0.06)$. The percentage reduction of basal $\mathrm{Rg}^{\prime}$ in WAT and BAT (61 and 71\% respectively) was greater than that observed in any other tissue. However, WAT and BAT showed differing responses to insulin elevation. At midrange hyperinsulinaemia, high fat feeding significantly reduced absolute $\mathrm{Rg}^{\prime}$ in both WAT and BAT, although the effect was much more pronounced in BAT (Table 4). In contrast to skeletal muscle and $\mathrm{BAT}$, the absolute difference in $\mathrm{Rg}^{\prime}$ between high fat and chow rats in WAT remained similar as insulin increased. In contrast to all other tissues, during hyperinsulinaemia $\mathrm{Rg}^{\prime}$ in heart for the high fat group was significantly higher than for the chow fed group (Fig. 2). As previously observed by us under similar conditions [20], the absolute level of $\mathrm{Rg}^{\prime}$ in heart in the chow fed group was lower in the maximal than in the midrange insulin clamp studies. This effect was also observed to some extent in the WAT responses.

The lung was mildly responsive to insulin elevation (approximately 2 -fold increases in $\mathrm{Rg}^{\prime}$ ). However, there was no difference between the two diet groups at midrange or maximal insulin elevation (Fig. 2). 


\section{Discussion}

The present study demonstrates that there is a considerable degree of whole body and individual tissue insulin resistance induced by a high fat diet in the rat. Our methodology enables a comparison to be made of the effects of high fat feeding on individual peripheral tissues. There is heterogeneity in the degree of insulin resistance among different tissues, and in particular among different skeletal muscle groups with major effects occurring in the principally oxidative muscles. Overall, whole body insulin resistance induced by a high fat diet is associated with a reduced ability of most skeletal muscles, and a number of other tissues with the notable exception of heart, to increase glucose uptake in the presence of a moderate insulin elevation.

It is of importance in our study that widespread peripheral insulin resistance has developed at an early stage of chronic metabolic alteration, and without evidence of basal hyperinsulinaemia or significant weight increase. Compared with the gross metabolic changes characteristic of genetic animal models of insulin resistance, such as Zucker "fatty" rats [21] the changes relevant to glucose homeostasis induced by several weeks of a high fat diet are quite mild. Some have found basal hyperglycaemia [5, 22], although in our study and in others $[8,23]$ this was not found. Other reports support our findings regarding the absence of basal hyperinsulinaemia $[6,24]$, although there is one report of mild basal hyperinsulinaemia accompanying high fat feeding [8]. Finally, while there is some evidence of increased adiposity in our high fat animals, as evidenced by increased epididymal fat weights, there was no significant difference in whole body weight (mean $+5 \%$ ) compared to chow fed animals.

Our methodology enables an assessment to be made of which peripheral tissues are most influenced by a high fat diet. An estimate of tissue glucose metabolic rate, the glucose metabolic index $\mathrm{Rg}^{\prime}$, is derived from uptake and phosphorylation of $3 \mathrm{H}-2$-deoxyglucose administered in the basal state or in the plateau phase of the glucose clamp. The method is fully described and the assumptions discussed elsewhere [14]. Deoxyglucose is present in trace quantities only and thus causes no metabolic perturbation.

Our studies suggest that peripheral basal glucose utilisation, while being significantly reduced in some tissues, is not altered to a major extent in most tissues by high fat feeding. Of the eight skeletal muscles studied, only diaphragm showed a significantly lower $\mathrm{Rg}^{\prime}$ in the basal state. We have thus been able to confirm in vitro data on the diaphragm [7], but it is clear that this metabolically active phasic muscle is not typical of the muscle mass. Our tissue data is consistent with a previous report of a small decrease (around 20\%) in whole body basal glucose turnover in high fat fed rats [5]. Despite the small overall change in glucose utilisation, there is some evidence of glucose sparing in peripheral tissues in response to a dietary carbohydrate lack. During high fat feeding, it is possible that the more metabolically active tissues, such as diaphragm and heart, shift more readily to lipid utilization than do less active muscles. Our data demonstrated a diet-induced reduction in basal $\mathrm{Rg}^{\prime}$ in heart of around 33\%. While this was not significant, probably due to the large group variance, others have reported in vitro data supporting reduced basal glucose uptake in the heart [9]. In addition, lung, which has a higher basal $\operatorname{Rg}^{\prime}$ than most muscles, and which can utilize lipids [25], exhibited a significantly suppressed basal $\mathrm{Rg}^{\prime}$ with high fat feeding.

In contrast to the selective alteration in peripheral basal glucose metabolism, widespread impairment of insulin action was found in peripheral tissues of high fat fed rats under conditions of euglycaemia and moderate $(130-150 \mathrm{mU} / 1)$ hyperinsulinaemia. This insulin elevation is the upper physiological range and approximates the whole body and mean muscle ED 50 for insulin enhancement of glucose utilization in the rat $[14,16]$. A significant reduction in insulin-stimulated $\operatorname{Rg}^{\prime}$ was found in six out of eight skeletal muscles studied. While this reduction varied over a 4-fold range in individual muscles, the mean reduction of $34 \pm 5 \%(n=8)$ suggested that the muscle mass is a major source of the whole body insulin resistance induced by high fat feeding. The present studies are in accord with other recent studies which demonstrate the importance of skeletal muscle in determining whole body insulin sensitivity $[16,18]$. Assuming that the muscle mass accounts for $50 \%$ of glucose disposal at this insulin level [16, 18], our results suggest that muscle could account for around half of the whole body insulin resistance found (i. e. difference in GIR at $150 \mathrm{mU} / 1)$. Further isotopic studies will be necessary to directly compare muscle versus liver insulin resistance (i.e. $\mathrm{Rd}$ versus $\mathrm{Ra}$ ) in the high fat fed rat.

Studies reported here of glucose metabolism in the presence of maximal insulin levels provide clear evidence of a loss of insulin responsiveness at both the whole body level and in the principally oxidative skeletal muscles (soleus, diaphragm and red gastrocnemius). These findings are in accord with previous in vitro findings concerning diet effects on glucose uptake in soleus [8] and diaphragm [7]. While it is possible that a loss of insulin responsiveness may be related to a diet-induced reduction of glucose transporters in muscle similar to that reported in adipose tissue [12], the possibility of pathway specificity in the diet effect suggests a multifactorial mode of action. In vitro studies suggest a greater effect on glucose oxidation rather than storage [7]. In support of this we have obtained a potent diet effect in diaphragm using a parameter related to total glucose transport and phosphorylation, whereas no effect was observed by others on 14C-glucose incorporation into glycogen in vivo [7].

Responses in white adipose tissue differ in several ways to that generally observed in skeletal muscle. Basal glucose utilisation is reduced with high fat feeding, 
consistent with reduced conversion of glucose to fatty acids [7]. There is an increase in adipose tissue mass, and it is possible that some of the reduction in glucose utilisation (per unit mass) is due to an increase in adipose cell size [26] and increased storage of lipids. Nevertheless, our studies would suggest, to the extent that an extrapolation from epididymal responses is valid, that there is a net reduction in adipose glucose metabolism in the basal state. This may not be the case during hyperinsulinaemia, however, as the percentage reduction in insulin sensitivity (around 30\%) is offset by the tissue hypertrophy. Thus a situation may be produced in the high physiological range of insulin elevation which preferentially increases adipose with respect to muscle glucose uptake, although the former remains small in absolute terms.

In contrast to muscle, there is no evidence of a reduction in incremental (insulin-stimulated minus basal) insulin responses to high fat feeding in WAT. This may reflect a different mode of insulin resistance in fat and skeletal muscle, although changes in adipose mass complicate interpretation. One factor may be the considerable diminution of hexokinase II activity induced by high fat feeding in WAT [27]. Our findings in WAT are qualitatively similar to previous in vitro findings [7] regarding suppression of basal glucose utilization and reduced insulin responsiveness induced by high fat feeding. The physiological significance, if any, of the apparent decline in $\mathrm{Rg}^{\prime}$ in WAT of both groups at high compared with moderate insulin elevations is not clear at the present time, although we have previously observed this response [30].

One of the most striking aspects of our findings was the contrast in responses in skeletal and cardiac muscle. While basal glucose utilization is reduced in hearts of high fat fed amimals in the presence of equivalent moderate or maximal insulin elevation, heart glucose utilization is enhanced in high fat compared with chow fed rats. We have recently reported [20], using our deoxyglucose-euglycaemic clamp technique, that high doses of insulin appear to be inhibitory to $\mathrm{Rg}^{\prime}$ but not to glycogen deposition in heart. A possible explanation that we proposed was feedback inhibition from glycogen deposition prior to the $3 \mathrm{H}-2 \mathrm{DG}$ administration. The present findings provide some support for this suggestion in that inhibition of $\mathrm{Rg}^{\prime}$ at high insulin levels was less evident in the high fat fed rats, which have lower cardiac glycogen levels (unpublished data). Thus there may be a greater shift from glucose to lipid utilization in the high fat fed group in the basal state. However, faced with a reduced availability of both circulating free fatty acids and stored glycogen, there is an increased need for heart glucose uptake during the hyperinsulinaemic clamp. This need could be further increased by stimulation of heart function by insulin [28]. Further studies of the cellular processes which could lead to these events are necessary.
Brown adipose tissue deserves special comment. Our studies demonstrate that in the chow (high carbohydrate) fed animal this tissue is extremely sensitive to insulin in vivo. Its uptake is some 30 -fold higher than white adipose tissue per unit mass, equals uptake in the heart, and exceeds that of all other tissues studied. High fat feeding induced profound insulin resistance in this tissue, although since it is present only in small amounts it does not represent a major factor in whole body insulin resistance. At an insulin level of $150 \mathrm{mU} / 1, \mathrm{Rg}^{\prime}$ in BAT differed in the diet groups by approximately $50 \mu \mathrm{mol} \cdot 100 \mathrm{~g}^{-1} \cdot \mathrm{min}^{-1}$. Given that interscapular BAT is $25 \%$ of total BAT mass [29], and a "lumped constant" (conversion factor of deoxyglucose to glucose metabolic rate) of 0.6 to $1.0[14,18]$, this would correspond to a total difference in glucose utilization of approximately $0.4 \mathrm{mg} \cdot \mathrm{kg}^{-1} \cdot \mathrm{min}^{-1}$. This is around $7 \%$ of the difference observed in whole body glucose utilization at an insulin level of $150 \mathrm{mU} / 1$.

We were unable to detect any effect of diet on the insulin response of the lung. The studies here confirm our previous findings that in vivo glucose metabolism in the lung is mildly sensitive to insulin $[14,30]$. The bulk of recent in vitro data now suggests that the lung is sensitive to insulin [31]. Methodological differences related to timing of labelled 2-deoxyglucose administration may explain why Hom et al [32] failed to observe in vivo insulin sensitivity in the lung. In their study, insulin and tracer are given together. Factors such as potassium shifts, free fatty acid suppression and enzyme activation, possible contributing factors to altered glucose metabolism, may be less important. Some of these factors are currently under investigation [20].

As the major effects of high fat feeding on alteration of insulin action occur in the range of insulin elevation seen after nutrient intake [33], and there are differing responses among peripheral tissues, it is likely that a chronic high fat diet will considerably alter the pattern of nutrient distribution after a meal. In particular, if a meal high in glucose is ingested, it is likely that glucose will be taken up in heart muscle in preference to skeletal muscle in subjects normally consuming a high fat diet. The possible pathophysiologic consequences of this need to be determined.

Finally, our studies have relevance to the aetiology of insulin resistance in man, and support the view that chronic basal hyperinsulinaemia may be a consequence, rather than a cause, of insulin resistance. We cannot determine, however, at this stage whether increased adiposity, although mild, is a necessary component of diet-induced whole body insulin resistance. There is evidence that increased adiposity is not necessary for diet-induced insulin resistance in adipose tissue $[11,12]$, although the situation in other tissues is not clear. Increased availability of lipids, either via the increased adipose mass, or via dietary hyperlipidaemia, may contribute to reduced muscle glucose uptake and oxidation [34]. Further studies are suggested, at both 
shorter and longer periods of dietary alteration, to determine whether whole body and individual muscle insulin resistance can be demonstrated prior to onset of increased adiposity, and to determine whether high fat feeding per se leads to the chronic basal hyperglycaemia and hyperinsulinaemia characteristic of other insulinresistant states.

Acknowledgements. We wish to acknowledge the expert assistance of S. Bennett with animal surgery. This work was supported by a National Health and Medical Research Council (Australia) Program Grant, and by the John Claude Kellion Foundation.

\section{References}

1. Sweeney JH (1927) Dietary factors that influence the dextrose tolerance test. Arch Intern Med 40: 818-30

2. Himsworth HP (1934) Dietetic factors influencing the glucose tolerance and the activity of insulin. J Physiol 81: 29-48

3. Christophe I, Mayer Z (1959) Influence of diet on utilization of glucose and incorporation of acetate 1-14C into liver fatty acids and cholesterol in rats. Am J Physiol 197: 55-9

4. Zaragoza-Hermans N, Felber JP (1972) Studies of the metabolic effects induced in the rat by a high fat diet. II. Disposal of orally administered (14C)glucose. Horm Metab Res 4: 25-30

5. Lavau M, Susini C (1975) U-14C-Glucose metabolism in vivo in rats rendered obese by a high fat diet. J Lipid Res $16: 134-42$

6. Bringolf M, Zaragoza N, Rivier D, Felber J-P (1972) Studies on the metabolic effects induced in the rat by a high-fat diet: Inhibition of pyruvate metabolism in diaphragm in vitro and its relation to the oxidation of fatty acids. Eur J Biochem $26: 360-7$

7. Susini C, Lavau M (1978) In-vitro and in-vivo responsiveness of muscle and adipose tissue to insulin in rats rendered obese by a high-fat diet. Diabetes 27: 114-20

8. Grundleger ML, Thenen SW (1982) Decreased insulin binding, glucose transport, and glucose metabolism in soleus muscle of rats fed a high fat diet. Diabetes 31: 232-7

9. Rattigan S, Filsell OH, Reppucci D, Patten GS, Clark MG (1983) Impaired basal and epinephrine-stimulated glucose uptake by hearts from rats fed high-fat diets. Nutr Rep Int 28: 603-12

10. Olefsky JM (1978) The effects of dietary carbohydrate content on insulin binding and glucose metabolism in isolated rat adipocytes. Endocrinology 103: 2253-63

11. Salans LB, Foley JE, Wardzala LJ, Cushman SW (1981) Effects of dietary composition on glucose metabolism in rat adipose cells. Am J Physiol 240: E175-83

12. Hissin PJ, Karnieli E, Simpson IA, Salans LB, Cushman SW (1982) A possible mechanism of insulin resistance in the rat adipose cell with high-fat/low-carbohydrate feeding. Depletion of intracellular glucose transport systems. Diabetes 31: 589-92

13. Bjorntorp P, Sjostrom L (1978) Carbohydrate metabolism in man. Speculations and some quantitative considerations. Metabolism 2 (Suppl 2): 1853-63

14. Kraegen EW, James DE, Jenkins AB, Chisholm DJ (1985) Doseresponse curves for in vivo insulin sensitivity in individual tissues in rats. Am J Physiol 248: E353-62

15. Defronzo RA, Jacot E, Jequier E, Maeder E, Wahren J, Felber JP (1981) The effect of insulin on the disposal of intravenous glucose. Results from indirect calorimetry and hepatic and femoral venous catheterisation. Diabetes $30: 1000-7$

16. James DE, Jenkins AB, Kraegen EW (1985) Heterogeneity of insulin action in individual muscles in vivo: euglycaemic clamp studies in the rat. Am J Physiol 249: E 567-E574

17. Kraegen EW, James DE, Bennett SP, Chisholm DJ (1983) In vivo insulin sensitivity in the rat determined by euglycaemic clamp. Am J Physiol 245: E1-E7
18. Ferre P, Leterque A, Burnol A-F, Penicaud L, Girard J (1985) A method to quantify glucose utilization in vivo in skeletal muscle and white adipose tissue of the anaesthetized rat. Biochem J 228: 103-110

19. Ariano MA, Armstrong RG, Edgerton VR (1973) Hindlimb muscle fibre populations of five mammals. J Histochem Cytochem 21: $51-5$

20. James DE, Burleigh KM, Chisholm DJ, Kraegen EW (1985) In vivo dose response curves of insulin action in heart: anomalous effects at high insulin doses. J Mol Cell Cardiol 17:981-985

21. York DA (1979) The characteristics of genetically obese mutants. In: Festing MFW (ed) Animal models of obesity. Macmillan, London, Basingstoke, pp 39-64

22. Zaragoza N, Felber JP (1970) Studies on the metabolic effects induced in the rat by a high fat diet. I Carbohydrate metabolism in vivo. Horm Metab Res 2: 323-9

23. Lawson N, Jennings RJ, Pollard AD, Sturton RG, Ralph SJ, Marsden CA, Fears R, Brindley DN (1981) Effects of chronic modification of dietary fat and carbohydrate in rats. The activities of some enzymes of hepatic glycerolipid synthesis and the effects of corticotropin injection. Biochem J 200:265-73

24. Lavau M, Fried SK, Susini C, Freychet P (1979) Mechanism of insulin resistance in adipocytes of rats fed a high-fat diet. J Lipid Res 20:8-16

25. Rhoades RA (1974) Net uptake of glucose, glycerol and fatty acids by the isolated perfused rat lung. Am J Physiol 226: 144-9

26. Salans LB, Dougherty JW (1971) Effect of insulin of glucose metabolism by adipose cells of different size. J Clin Invest 50: 1399-408

27. Bernstein RS, Marshall MC, Carney AL (1977) Effects of dietary composition on adipose tissue hexokinase-II and glucose utilization in normal and streptozotocin-diabetic rats. Diabetes 26: $770-9$

28. Liang C-S, Doherty JU, Faillace R, Maekawa K, Arnold S, Gavras $\mathrm{H}$, Hood WB Jr (1982) Insulin infusion in conscious dogs. Effects on systemic and coronary hemodynamics, regional blood flows and plasma catecholamines. J Clin Invest 69: 1321-36

29. Cooney GJ, Newsholme EA (1984) Does brown adipose tissue have a metabolic role in the rat? TIBS $25: 303-5$

30. James DE, Kraegen EW, Chisholm DJ (1985) Effects of exercise training on in vivo insulin action in individual tissues of the rat. $\mathbf{J}$ Clin Invest 76: 657-666

31. Friche RF, Longmore WJ (1979) Effects of insulin and diabetes on 2-deoxy-D-glucose uptake by the isolated perfused rat lung. J Biol Chem 254: 5092-98

32. Hom FG, Goodner CJ, Berrie MA (1984) A 2-3H deoxyglucose method for comparing rates of glucose metabolism and insulin responses among rat tissues in vivo. Validation of the model and the absence of an insulin effect on brain. Diabetes 33: 141-52

33. Strubbe JH, Steffens AB (1975) Rapid insulin release after ingestion of a meal in the unanaesthetized rat. Am J Physiol 229: $1019-22$

34. Lillioja S, Bogardus C, Mott DM, Kennedy AL, Knowler WC, Howard BV (1985) Relationship between insulin-mediated glucose disposal and lipid metabolism in man. J Clin Invest 75 : $1106-1115$

Received: 3 September 1985

and in revised form: 30 December 1985

Dr. E.W. Kraegen

Garvan Institute

St Vincent's Hospital

Sydney NSW 2010

Australia 